\title{
Study on Problems and Countermeasures of Textbook Management in China Universities
}

\author{
Lihua Geng \\ Changchun University of Science and Technology \\ Changchun 130022, China \\ E-mail: glh@cust.edu.cn
}

Received: July 16, $2011 \quad$ Accepted: July 25, $2011 \quad$ doi:10.5539/ies.v4n3p224

\begin{abstract}
Textbook management in universities is an integral component of teaching management. With gradual development of university education teaching, textbook management in China universities can no longer keep pace with the steps of the teaching management, and the work of textbook management is faced up with new challenges. This article makes an analysis of problems existing in textbook management in China universities and proposes relevant countermeasures to achieve a virtuous circle between textbook management and teaching management, ensure adaptation of textbook management and teaching management and facilitate development of textbook management in universities.
\end{abstract}

Keywords: Problems, Countermeasures, Textbook management, Universities

\section{Analysis of the Status Quo of Textbook Management in China Universities}

\subsection{Diversification of Textbook Management Initiated by Development of Discipline Construction}

With rapid development of higher education in China, demand of extension on knowledge and on textbooks by all majors is on a daily increase. Newly added majors also increase the strength of investment in construction of textbooks. A large majority of universities are taking an initiative to broaden the professional channel in their construction of disciplines and run the schools with multiple levels and multiple specifications to enable the scale of the school running expanded year by year. In the meanwhile, in the process of discipline construction by the most universities, construction of top-quality course, excellent course, key profession and particular profession can't go without selection of excellent textbooks.

Thus, with development of discipline construction, not only demand on textbooks is on a daily increase, but also diversity and variety of textbooks are required. As for textbook management practitioners, diversification of the work does not only lie in professional textbook management, but also in discipline overlapping of different professions, which requires the management scope of original textbooks to be further expanded.

\subsection{Complexity of Textbook Management Caused by Expansion of the Teaching Scope}

With adjustment of all universities in their teaching plans, they reduce the varieties and class hours of compulsory courses, while the varieties and rate of selective courses are increased. They also add the ratio of bilingual or multilingual teaching, increase the ratio of courses taught in English and extend the scope of teaching courses. In this way, students can learn according to their own situations through compulsory and selective courses. In terms of selection of textbooks, the original fixed textbook management mode is broken, and the independent textbook selection mode is realized for students and teachers, which can make the original textbook management mode more complicated.

\subsection{More Complicated Selection Mode of Textbooks Caused by Development of Modern Educational Technology}

With expansion of modern educational technology in college teaching, more and more teaching content depends on modern teaching means and teachers attach more and more importance to the supportive multimedia courseware for courses in selection of textbooks. At the same time, as for construction of network courses, the multimedia courseware plays an important role in supporting the content. Although more and more publishing houses furnish supporting multimedia courseware CDs in their publishing textbooks, it is often that adaptation between teaching of the courses and the courseware offered is not consistent. Although some textbooks have not offered multimedia courseware, they are quite adaptive to teaching of the courses. Thus, selection of textbooks that are related with modern education technology in management of textbooks becomes more complicated. Not only teachers should be 
encouraged to adapt to the multimedia courseware, but they have to make evaluation on the adaptation of the courseware, which adds to the work of textbook management personnel in selection of traditional textbooks.

\section{Analysis of Problems Existing in Textbook Management in China Universities}

There still exist a lot of problems in the process of textbook management in universities, which can't satisfy requirements in textbook management and makes the efficiency of textbook management process low, all these problems urgent to be resolved in textbook management.

\subsection{Lack of Management in Selection of Textbooks and Lack of Scientific Evaluation Tools in Selection of Textbooks}

Different universities have great randomness in selection of textbooks and low optimization rate. Since the mechanism of universities in selection of textbooks in not perfect, there exists the trend of simplification in selection of textbooks. Blind continuity of repetition and copy of textbooks and lack of extensive information and effective mechanism restraint in selection of textbooks causes teachers to depend on employing familiar textbooks in selection of textbooks. When they select relevant textbooks for former teaching courses, they don't make a preferential choice and contrast of textbooks, which causes evaluation of textbooks unable to achieve the anticipated effect. Teachers ignore excellent domestic textbooks, still adopt traditional teaching mode for courses with strong bilingual teaching features and repeat the previous textbooks, all of which makes it difficult for the textbooks selected to have its due effect in the process of teaching. There are usually two means in selection of textbooks by teachers. On one hand, they select according to relevant revision catalogue of the textbooks. Since they can only come to know some basic information and they are deficient in rational recognition of the real objects, so this means has certain limitations. On the other hand, teachers subscribe and revise textbooks according to existing textbook objects or textbooks that they have read. Although they have an overall idea, also there exists certain one-sidedness or contingency. For the time being, publication and update of textbooks is fast, whereas information source of teachers is limited. Therefore, it is difficult for teachers to have a complete mastery of data about relevant textbooks. Limitations of the scope of teachers' selection of textbooks will necessarily affect selection of the textbooks.

Currently, textbook management sections in lots of universities have not paid enough attention to quality of selection of textbooks, where the scientific evaluation instrument for selection of textbooks is generally lacking. Course teachers are the first to select the textbooks, while they only select those versions of textbooks that they favor in the process of selecting textbooks, which is not determined by the entire teaching and research section. It is often that when new course teachers take the turns to teach the courses, they eliminate the former textbooks and select other textbooks, which leads to great randomness in selection of textbook versions. Some teachers do not update new and excellent textbooks for convenience of preparing their classes after having used a version for several school terms, which causes textbooks that reflect new scientific knowledge unable to be timely selected and the quality of teaching unable to be improved. After the textbooks selected are used, feedback of teachers and students is an important component in a stereo evaluation on the textbooks. At present, quite a lot of universities are lacking in the consciousness of a whole process supervision on the quality of textbooks.

Some universities are in chaos in selection of textbooks, which causes some human relationship textbooks flow into the classroom, whereas national, provincial and ministerial excellent textbooks can't get employed, which affects preferential selection of textbooks. Some textbooks are usually sold with exclusive selling rights for several years on end. Thus, although new versions of textbooks come to birth, those textbooks sold with exclusive selling rights have to be accommodated to be used due to the economic benefits of these textbooks, which seriously affects the selection of textbooks with high quality.

\subsection{Lack of Modernized Management Means in Management of Textbooks}

Usually, textbook management personnel have no clear idea about functions of textbook management and mistakenly believe that management of textbooks is nothing more than to order and issue books to students and it is all that students have books to learn when the school starts. Thus, their requirements on management of textbooks are low. As a result, this will necessarily lead to low efficiency of textbook management. Since the textbook management department loses a subjective controlling consciousness in construction of textbooks, randomness is caused in construction of textbooks by the university faculties. Even if they have any plan, it is usually that the plan is laid aside and neglected as a result of the difficulty in implementation of the plan. Besides, financial investment in textbook management in universities is also quite obvious.

With increasing work on textbooks, textbook management also becomes increasingly complicated, and the original manual management becomes more and more unable to keep pace with development of the times. The original manual textbook management is laggard in terms of work means, with low work efficiency, which seriously constrains the development of textbook management. On one hand, work amount of textbooks is added, and 
especially when the credit system is put into practice, the randomness of students' selecting courses becomes more obviously, which breaks through restraints of professions, departments and subjects. At the same time, due to unconstraint by the length of schooling, the varieties of selective courses are on the increase, as a result of which the number of students who select a definite course has no way to be calculated accurately, which more adds to the difficulty in the textbook management. On the other hand, some universities still haven't placed enough emphasis on management of textbooks and have not had enough investment in textbook management. Besides, corresponding computer software hasn't been applied into textbook management and their working means still remains on the level of manual operation, which is far from adaptation to the requirements of reform in university textbooks.

Although textbook management offices in some universities have been equipped with computers, these computers are regarded as nothing more than the tool for recording textbook data and for statistical calculation, and the textbook management has not yet been brought into the teaching management network. Corresponding computer software has not been applied to textbook management, and their working means still remains on the original manual operation, which has great amount of work, single, repeated, tedious, and easy to make mistakes, which exerts influences upon successful teaching and which is far from adaptation to the requirements of reform in university textbooks.

\subsection{Problems Existing in Compilation of Textbooks and Selection of Textbooks}

\subsubsection{Awarding of textbooks is prior to compilation of textbooks}

With further reform in teaching of all universities, these universities attach great importance to the achievement of self-compilation of textbooks. It is often that any provincial (ministerial) and national rewards brings perfect demonstration effects to evaluation on teaching quality and evaluation on talents and scientific findings. However, strict and meticulous flow and working procedures are required for self-compiled textbooks from the project approval to the compilation and until the publication, which is aimed to certify that the quality of the textbooks complies with the standard of excellent textbooks. For the time being, the funds in compilation of textbooks in lots of universities are burdened by teachers themselves who are faced up with conferring of academic titles within a short period of time or who are driven by economic benefits. Therefore, they have no means to put more energy for compilation and argumentation of the textbooks. Moreover, what universities focus on is whether the textbook compilation will get a reward after its publication. Insufficient investment leads to the result that lots of textbooks with similar types may be put into use in the classroom after being packaged by the teachers, while the quality of these textbooks are intermingled.

\subsubsection{Selection of textbooks is random and quality control of textbook selection is relaxed}

Different universities have strict requirements on selection of textbooks. However, under the current circumstance, usually it is teachers who determine the content of textbooks and the teaching and research section and the faculty have neither determined the textbooks in strict accordance with the collective discussion, nor have submitted the content of the textbooks to those who are in charge of the teaching content for approval. In the mean time, the same teaching and research section participates in compiling the textbooks. Thus, there is no one who cares about the content of the textbooks. As a result, after the content of textbooks is submitted, it is often that textbooks have not been printed and that human relationship textbooks and textbooks for academic titles overflow.

\subsubsection{Evaluation of excellent textbooks is simple and the standard of textbook selection is too general}

Each university organizes evaluation on excellent textbooks each year with the purpose of pushing forward construction of textbooks and encouraging teachers to edit or take part in compiling the textbooks. Since the experts invited by the universities from outside have limited time, and their professions are not necessarily the competent subject within the professional scope, together with long review cycle and high review expenses, usually it is difficult for universities to invite excellent experts in the universities to conduct the review process, and they often organize the experts and members who are in charge of the teaching of the faculty and who have the right to determine the textbooks within the professional field. However, when it involves textbooks of other fields, they are unable to put forward professional opinions. Thus, the relevant review documents they work out are bad in maneuverability for they are unlikely to play the standard role of review.

\section{Analysis of Relevant Countermeasures in Textbook Management in Universities}

As for problems existing in textbook management in universities, we ought to take relevant measures to ensure the successful running of textbook management in universities. Thus, textbook management in universities should be done from the following several aspects. 


\subsection{Scientificalness of Textbook Management}

\subsubsection{Scientificalness of textbook selection}

For the time being, universities attach little importance to research of textbooks, which is the weakest aspect in textbook management. Selection of textbooks should be conducted on the basis of research of textbooks and according to rules and regulations as well as procedures to select textbooks. Selection of textbooks is the key to the textbook management. Thus, we should not only select high quality and excellent textbooks, but should select textbooks with strong adaptation. Meanwhile, the textbooks selected should possess the characteristics of the times and advance with the times. We should encourage self-compilation of teaching materials and textbooks, which should be combined together with bilingual teaching. We should also select foreign high quality textbooks that suit with the reality of the universities and prohibit bind introduction of textbooks without selection. Selection of textbooks has to be managed in a scientific way so as to guarantee quality of the textbooks selected.

\subsubsection{Scientificalness of textbook construction}

Textbook construction is an important component of textbook management, for the quality of textbook construction has great influences upon textbook management. The key to textbook management is the compilation of textbooks. Thus, the quality in compiling textbooks has to be seriously controlled and teachers who are have high academic level and have rich teaching experiences for several years and rigorous teaching styles can be organized to compile textbooks in strict accordance with the teaching syllabus and cultivation targets, persisting in the principle, scientificalness, advancement, adaptation and pioneering features, strengthening basic knowledge, basic theory and basic skills in the content of teaching, taking the latest research findings in the new theories and new methodologies of the research field of the subjects and highlighting cultivation on students' innovative ability as well as broadening students' scope of knowledge. At the same time, the universities ought to organize experts to make strict evaluation on the textbooks they have compiled.

\subsection{To Strengthen Textbook Research and to Make Efforts to Push Forward the Project of Construction of Excellent Textbooks}

Since the phenomena of outdated content of some textbooks, repeated compilation of textbooks, lack of characteristics of textbooks and low quality of textbooks, it seems especially important to further strengthen and enhance research of textbooks. Textbook research is an important measure to enhance compilation and textbooks and improve quality of textbook selection. Thus, universities should take an initiative in research on the content and system of textbooks and on evaluation of higher education textbooks, indexes of selection quality and implementation methods, etc., organize management of project approval of subjects and furnish corresponding funds support. As a textbook management department, the first thing to do is to completely exercise the autonomous right of selection textbooks, encourage experts and scholars to extensively develop textbook research and textbook evaluation activities according to the school running features of different professions, teaching reality and their own teaching experiences, vigorously make propaganda evaluation and recommendation on those textbooks that have been published, intensify propaganda and recommendation on excellent textbooks of the universities so as to expand the influences of the excellent textbooks, introduce excellent textbooks in the universities both at home and abroad, perfect the system of textbook selection management, give priority to selection of provincial and ministerial excellent textbooks and key textbooks so as to guarantee that textbooks with high quality are introduced to the classroom. At present, the biggest deficiency in compilation of textbooks is that teachers of the same university compile the textbooks, publishing house of the same university publishes the textbooks and students of the same university apply the textbooks. The outcome is that, the academic accumulation is not sufficient and exchange of information is not sufficient, which is likely to give rise to academic barrier and which inevitably will cause negative influences upon teaching. Thus, the universities have to put an effort to develop textbooks with originality, break through the academic barrier, break down the situation of "closed operation within the system" of the textbooks, strengthen cooperation of textbook construction and enable students to acquire more extensive knowledge system. Then, the universities have to update the textbooks in due course to enable the textbooks to always fir with the teaching and academic level of the development of the subjects and to enable the textbook system to be more perfect and rational.

\subsection{Emphasis on Management of Selection of Textbooks}

We should strictly control the quality of textbook selection according to regulations and requirements of selection of textbooks by competent departments of the country in selection of textbooks and try to select and revise course textbooks in the Twenty-first Century and those excellent textbooks which have been awarded as national, provincial and ministerial rewards. Then, the state-complied textbooks and textbooks that are published by university publishing houses are selected and revised. Afterwards, textbooks published by local publishing houses 
can be selected. There should be different levels in selection of textbooks, which should be combined with characteristics of the courses. An analysis can be made for practical applicability of textbooks according to bilingual teaching and courses that are taught in English so as to really realize the effect that selection of textbooks not only suits with teaching of teachers, but also adapts to learning of students, and meanwhile, that selection of textbooks should adapt to construction of textbooks and requirements of discipline construction.

In addition, at the time when universities lay emphasis on selection management of textbooks, they should also encourage their teachers to compile textbooks or teaching materials by themselves. Especially, senior teachers with abundant experiences should compile textbooks or teaching materials that are full of the features of the university itself and adapt to the actual situation of the university according to their experiences and understandings of the courses they have taught. The universities should also improve rational selection of textbooks, which might have great effect on ensuring and enhancing quality of teaching. Discussion on courses should be conducted with a course production team as one unit to compile textbooks by selecting advantages of several textbooks. They can also combine the courses with the professional research field according to the teaching objects and professional features of the courses that are taught. The textbooks that are compiled in this way can realize improvement of the teaching quality of this profession.

\section{Conclusion}

Textbook management is an important supplement component in teaching management in China universities. In order to improve the importance of textbook management in teaching ancillary work, we need to make a general plan on the features of textbook management, textbook research and textbook selection and make a selection in allusion to features of textbooks for different courses, encourage university teachers to compile textbooks by themselves, select the best among the best of textbooks and guarantee the synchronicity and adaptation of textbook management and course teaching.

\section{References}

Hu, Ge. (2011). Characteristics and Countermeasures of College Textbook Management Work at a New Period. Journal of Inner Mongolia Normal University, (5):35-37.

Huang, Li. (2011). Discussion on Several Issues Existing in College Textbook Management. Journal of Management Sciences, (2):116-117.

Liu, Ke \& Liu, Aiying. (2010). Reflections on Pushing forward Reform and System Construction of College Textbook Management. China Adult Education, (9):41-42.

Wang, Xiaoyan. (2008). Study on Status Quo and Countermeasures of College Textbook Management. Forum on Contemporary Education, (7):52-53.

$\mathrm{Xu}$, Qinghong. (2007). Some Reflections on the Reform of Administration of College Teaching Material. Xuzhou Institute of Technology, (11):84-85. 